Adam Reed, University of St Andrews

\title{
Reading Minor Character: An English Literary Society and its Culture of Investigation
}

\section{Introduction:}

'What character in Henry Williamson's writings fascinates you?' The question, circulated prior to a branch meeting of the literary society constituted in the author's name, defined a typical line of inquiry among the readers I came to know well. At this particular gathering, held in the conference room of an ungainly brick and glass-fronted theatre complex in the Surrey commuter belt town of Redhill, members were instructed to come prepared to talk. Once settled, the Chair of the branch meeting stood to welcome the thirty or so men and women present. He then invited individuals from the audience to come up and speak about their chosen character.

After an initial silence, a woman in her late sixties rose and told us that her favourite character was Spectre West, the commanding officer of the protagonist from Williamson's First World War books. She went on to tell us how much she admired this secondary character and to outline why she thought him important to the novels as a whole. Brief applause and thanks from the Chair led into comments and opinions from the floor, and to a flurry of other speakers. For instance, a man in this crowd conspicuous by his relative youth (in his early thirties) stood and announced that he wanted to talk about Julian Warbeck. Everyone laughed. The character, an occasional companion to the protagonist Phillip Maddison across the same cycle of novels, was famous to all as a notorious drunk. The next speaker, a man in his mid seventies, declared that some of his favourite characters were 'very minor', the ones that Williamson 'deals with in a page or so and then they disappear.' By way of illustration, he read aloud an extract from one book that describes Mrs Low, a working class woman who sews clothes for Phillip's mother. In his thanks, the Chair agrees that it is true that a lot of the minor characters in the novels 'stay in the mind'. Under pressure from his fellow members, he concluded by sharing his own choice, a tragic figure named Hugh Turney. As the maternal uncle of the protagonist, he told us, this character appears in several books and that despite Hugh's untimely death midway through the fifteen-volume cycle many further references are made to him.

This kind of occasion would be well known to those who have attended the meetings of any number of literary societies; although often conceived as anachronistic and old-fashioned, the literary society is in fact a live and expanding phenomena on both sides of the Atlantic. Indeed, as well as the continuing constitution of societies for contemporary or recently deceased writers, the last forty years have seen new associations formed to celebrate the works of those long dead. In the United Kingdom, for example, literary societies for figures such as Anthony Trollope and Virginia Wolf were formed as late as the 1990s; and the Jane Austen Society of North America was only founded in 1979 (see Johnson 2012). Drawn from my ethnographic research with members of The Henry Williamson Society-a British body of readers founded in 1980 and 
supported by the author's literary estate who are enthusiastically dedicated to the promotion of the twentieth century English historical novelist and nature writer-the scene above captures a familiar form of sociable exchange between them. Like other literary societies, the organisation is structured through textual correspondence, via the circulation of a Society newsletter and journal, and through the arrangement of a series of annual gatherings. As well as regional branch meetings in venues like Redhill, there are regular themed trips or weekend stays in locations closely connected to the novels, such as North Devon, and a formal 'Study Day', usually organised in Central London. At these events, members from across England and Wales join together to publicly share their love of the works of Williamson and then disperse, back to their individual homes and solitary acts of reading.

Alongside biographical presentations on the life and work of Henry Williamson (1895-1977) and talks about the themes and landscapes of the novels, they also meet to hear reports on the private studies of fellow members into the novels' minor characters. These reports can be made through the kind of audience discussion already described, but equally by a formal lecture given at a Study Day or as a slide show presentation on a weekend away. In the latter case, character chat often runs over into conversations at dinner or at drinks in the hotel bar; in all this talk, there seems a common assumption that a member's favourite character will invariably be a secondary one. Indeed, this emphasize on the value of investigating minor character is an important basis for one of the defining features of their interaction: the individual but shared commitment to rereading (an aspect of literary society life that perhaps provides one general point of distinction to the activities of book clubs and reading groups). As Society members point out, an interest or identification with secondary character precisely emerges out of this practice; individuals typically claim that they often only notice such characters upon repeat readings. Likewise, it is often that desire to know minor character that prompts multiple reading of the same novel. Regularly contrasted by them with the first enraptured and solitary event of reading Williamson, presented as the initial spark for enthusiasm, rereading for minor character is acknowledged as a pleasurable kind of labour that helps sustain a more sober zeal both for the author's oeuvre and for their continued coming together.

In this essay, I am concerned to explore, from an anthropological perspective, the basis for engagement and assessment of minor character by these readers. Necessarily, it involves me invoking the contingency of ethnographic example-a wish to emphasize how this activity must be placed or understood in the context of an actual reading culture but also an ambition to let that 'culture' reveal itself through the specific ways the encounter with minor character is enacted by Williamson readers. As is conventional in anthropological approaches, the onus on ethnographic description is married to a desire to locate an analytical language that can simulate the dynamism and stages of interaction that subjects themselves identify. For me, a further part of the challenge lies in the fact that my previous writings on The Henry Williamson Society have begun with and worked through the assigned primacy of enraptured reading (see Reed 2002, 2004, 2011), which has provided the explanatory motor for much of my description (including my past brief accounts of character reading). Although I will eventually return to this crucial event in 
the lives of Williamson readers, I want here to experiment with a description that begins elsewhere, with acts of rereading, labours of private study and the relationship to secondary characters. What inspires this commitment? Where does the interest lead and how might it animate (or re animate) the connections that matter in the sociable and solitary reading practices of Society members?

To help address these questions and trace the significant movements in the reception of literary character by Henry Williamson Society members, I turn to the work of Gell (1998). His redefinition of the anthropology of art provided a vital stimulus and operational language for my original description of the literary society as a culture enlivened by the drama of enraptured solitary reading (figured by Williamson readers as akin to a form of authorial possession). This made sense because a large part of Gell's innovative approach-developed at the same time but quite separately from the actor network theory of science and technology studies with which it may be taken to resonate-centred precisely on observations about the dynamic and animating potential of claims made by the identified recipient of action. ${ }^{1}$ It was the crucial addition of what he termed the 'patient' position that for many marked his approach out, not just within the anthropology of art but more broadly within new anthropological studies of materiality (1998: 22-23; \& see Strathern 1999; Henare, Holbraad \& Wastell 2007). Indeed, for Gell, the patient, the figure that is held to be acted upon (or through) in the interactions around a specific art-object, plays as a central a role as the figure that is understood to be exercising that creative agency. Both may be taken to be 'effectual actors' (Strathern 1999: 17); this emphasis differentiates Gell's approach from actor network theory as well as most theories of reception. When Gell speaks of 'agency' then, it is not just that he is wanting to move beyond a definition exclusively attached to human will or intention, to acknowledge for instance the entanglement of human and non human actants; rather he wants to describe the fluidity of forces that register an impression in the vicinity of the art-object. In this account, both persons and things may be valued as either agents or patients in a whole dynamic nexus of agent-patient relations. The insight allowed me to previously recognise Williamson readers as effectual actors who, through singular but mutual experiences of enraptured reading, saw themselves as vital indexes of the impact of authorial intelligence and action. But I want to argue that it might also operate as a means for exploring subtler impacts and the patient-agent interactions that inform relationships between readers, literary characters and the assigned sources of depiction.

Attention \& Neglect:

As Strathern (1999: 17) highlights, Gell provides an approach to art centred on the 'analysis of relational effect'. An agent requires the existence of another to have its effect registered, likewise a patient requires a counterpart who is seen to cause an event to happen. The point might be reiterated by turning to one literary theorist whose observations on the importance and power of minor characterisation strike me as providing a useful entry point for anthropological interpretation.

According to Woloch (2003: 37), readerly interest in secondary characterization is driven by the tension or 'dissonance' between the presence of the character on the page and its wider influence in the story. For him, this 
works through what the reader is told about secondary character and through what is not said; minor characters' defining qualities lie not just in their limited appearance "but in the very manner in which they are "absorbed" in or "expelled from" the novel' (38). This includes the way in which minor character gets 'drowned out'. One of the ways in which this general explanation of the effects of minor characterisation upon the reader becomes interesting for anthropology is in the account Woloch goes on to provide of how this overshadowing or drowning out actually plays out. In particular, I am drawn to his account of the interactive or 'dynamic flux of attention and neglect' by which characterisation works (1). It is a commonplace observation in criticism that minor character exists to serve the story and throw fresh light on the central consciousness of the protagonist, whose world or larger narrative context is itself made manifest by the multiplicity of secondary characters; however, the language chosen by Woloch to illustrate this is, I think, intriguing. He invites us to view both minor and major characters in a 'distributed field of attention' (17), with each one dynamically shifting to either give attention (or neglect) to another character or to receive attention (or neglect) from someone else. The 'social' dimension of such interactions may highlight the degree to which minor characters are usually reduced to operating as attention-givers or neglect-receivers but also suggests the possibility of redistribution. Indeed, Woloch argues that the 'formed pattern of attention' in the narrative discourse of the novel is always vulnerable to alteration (41). The literary text solicits 'disjunctions between the attention the discourse grants certain characters and the attention that they would grant themselves and that the reader might grant them'. So, rather in passing, he offers us a theory of reception precisely grounded in the reader's own act of giving attention (and neglect) to literary character. In this essay, I am interested in exploring this idea or perhaps more accurately redeploying it anthropologically, which by implication includes the concomitant notion that the reader might also adopt the position of attention (or neglect) receiver.

Woloch's whole relational language of distributed attention and neglect is also a useful way of bringing us back to the novels of Williamson that formed the basis for Society members' investigations of minor character. For the fifteenvolume novel-cycle, entitled A Chronicle of Ancient Sunlight, upon which much of the private labour and public expression of interest in secondary characters is based, makes the consequences of role-bearing and inattention within generations of a family and English society at large a central theme. As readers constantly emphasize, this roman fleuve, which Williamson hoped would stand comparison alongside the historical novel-cycles of Tolstoy and Galsworthy, is concerned to explore how characters react and become influenced by the love or lovelessness shown by others. At its heart is an account of the life of the protagonist, Phillip Maddison, and the consequences of an upbringing in a late Victorian household with a loving mother but dominating and resentful father. The novels focus not just on what particular kinds of fatherly and motherly attention produce in those who are its recipients, but equally on the frustrations and burdens of those roles. Neglectfulness by the father is shown to be the outcome of the inattention of his father before him, just as the roles of fathering and husbanding itself are shown to constrain what a person might be. Here there is a tension between individual person or being and persona, including the personas or roles of kinship. It is the frisson provided by such tensions that 
Society members appreciate and sometimes identify with. As one reader told me, Williamson's 'greatness' lay in the fact that he 'understood the cycle of cause and effect.' Indeed, at times readers seem to describe both the characters in the novels and themselves as, to invoke Gell again, certain kinds of patient (i.e. subjects whose actions principally register the effects of attention or neglect by others).

As I will explore, there is a sense then in which Society members export the notion of minor character to provide a description of their own subject position in the world. They sometimes feel very minor indeed, the product of neglect but also of roles that demand they give attention in specific directions. This includes a sense that attention flows away from them, towards a centre that lies elsewhere (readers do not always figure themselves as the protagonist in their own life stories) and a sense of being encumbered by the attentions of others (children, spouses, work colleagues). There is even a keen awareness of their own imminent disappearance; due to the average age of readers the Society must annually announce the death of a few of its members (unlike fan fiction, which is typically described as driven by the enthusiasm of teenagers or adult readers in their twenties and thirties, literary societies, at least in the UK, tend to attract the majority of members when readers have entered late middle age or retirement years). But the struggle with minorness is also a defining quality of Society action. One of the reasons readers join the literary society and attend its events is because they feel the public neglect of the author and his works. As they are painfully aware, Williamson's novel-cycle has not achieved the prominence of those works authored by Tolstoy or Galsworthy. Resentment at the lack of attention thrown on Williamson and his works and the subsequent suspicion that the author risks being dismissed as a minor writer is coupled with an anxiety that Williamson might receive too much of the wrong kind of public attention (i.e. that centred on authorial notoriety). However, I want to come at these issues through the prism of Society members' minor character investigations. For it is these practices, I argue, that provide individuals with one technology for addressing the concerns of The Society. ${ }^{2}$

As well as the tension created by the overshadowing or asymmetries in the formed pattern of attention between characters, Woloch identifies a further dissonance that may generate sympathy in the reader. Our interest in the fate of minor character, he argues, is also fuelled by a sense of its reference to humanness or the 'implied person' (2003: 13) that lies behind it. This is, as it were, a concept of the person that we might identify as inherent to minor characterisation itself, as opposed to one introduced by the theorist. Woloch then is interested in how minor character also expresses 'the impact of a human being' (2003:11); his is a quite conscious attempt to remediate the traditional opposition between formalist and humanist forms of character-criticism (2003: 16-17). We need, he argues, to acknowledge that the power of literary character lies in this very division, between its structural relationship to other characters in the narrative discourse and its specific reference to a hinted at individual being. This is an account then that would privilege 'not how the literary form, in its intricate coherence, is rendered into a living organism, but how living persons get rendered into literary form' (2003: 11). The emphasis is important and returns us to the tension that Woloch claims drives a readerly engagement with secondary character. For, 'how can a human being enter into a narrative world 
and not disrupt the distribution of attention?' (2003: 26). It is this referential status of minor character, its implied person, that makes the reader feel its narrative position is always restrictive, and which in turn motivates an interest.

Anthropologists would of course be fascinated by any attempt to examine the assigned impactfulness of human being (anthropological description may insist upon difference and relativize accounts of humanness, but it rarely portrays human being as itself an action that subjects experience as eventful) and by the suggestion that a concept of person may here operate more through its implication and 'stinting' (Woloch 2003: 12) than through its illustration or enactment. I am especially drawn to the way Woloch presents the dissonance through figuring it as a dilemma of functionality or duty. The minor character, he states, is 'an implied human being who gets constricted into a delimited role, but who has enough resonance with a human being to make us aware of this constricted position as delimited' (2003: 40). Of course Woloch's theory only works by assuming the existence of a general reader; the 'us' of which he speaks is ill-defined and immediately problematic for an ethnographic description. However, the emphasis still strikes me as suggestive. One of the ambitions of this essay is precisely to chart how and when Williamson readers feel the impact of a person 'behind' literary character. This includes an exploration of the shifting temporality and flows of agency identified between secondary character and implied human being (what Gell would term the 'prototype' relationship), but also the way those patient-agent interactions open up avenues for the redefinition of the kind of effectual actor that a reader can be.

\section{Actualisation:}

'Have a look at that.' Derek handed me a pink folder stuffed full of typed pages with the word 'Index' printed in bold on the front cover. 'There's over seven thousand references in that thing,' he told me. As I flicked through the pages, he directed my attention to a large section entitled 'Richard Maddison' and to a series of subsections that listed 'Name,' 'Date of Birth,' 'Ancestry,' 'Appearance,' 'Characteristics,' 'Personality,' 'Butterflies,', 'Reading,' 'Cycling' among its classificatory categories (the latter three being well-cited hobbies of this secondary character). I already knew of Derek's interest in Richard Maddison, the stern and frustrated father of the protagonist in Williamson's A Chronicle of Ancient Sunlight, because he had given an after-dinner talk on the character at a previous weekend meeting of the Society. But on this occasion, we were sitting alone at the dining room table of his detached pebbledash house, which he and his wife owned in the Welsh city of Newport. Derek explained that he first came across the books in the town's central library while he was still working as a branch manager of a retail bank. Those first readings sparked a passion for the works of Williamson, which has led him since his retirement to devote long hours to the study of the novel-cycle and in particular to an examination of certain minor characters.

Derek told me that he chose to study Richard Maddison because 'the guy attracted me, I liked to read about him because he was believable.' This was the case even though he didn't like the character as a person; 'I mean he was sort of a monster in a way, he was never deliberately cruel I don't think but he was convinced he was always right, very blinkered.' Like other Society members who do this kind of work, Derek had begun his investigations through a commitment 
to index the number of times that the character makes an entry across the novelcycle. Indeed, upon each rereading of the books the size of his pink folder had grown. As well as listing Richard Maddison's appearances, Derek started to index the number of times other characters referenced him and what they said. He also started to document those even more minor characters whose own appearance depended on this figure; for example the neighbours of Richard when he first moved to the South London suburb where he married, raised his family and spent his working life, or his colleagues at the insurance company in the City. It should be noted that as with a lot of other Society members all of this labour was done without the assistance of a computer; instead of relying on the search facility available for electronic files, Derek pasted marks and highlights in the copies of his well-thumbed paperbacks. Again, like others who did this, he emphasised that the work of indexing, giving public talks and publishing his findings in the Society journal was first and foremost a form of service to his fellow Williamson readers. He told me, 'I write a piece on Richard, not so much giving my opinions on him because Henry does all that for us, but to gather what we know about Richard from all the different books and put him in a box if you like, condense a whole number of novels into a few pages so people can read all about him.' This form of parcelling or condensing was very much seen as a favour for the re reader, someone who would take the material offered as a prompt to go back themselves to the novels and dig out more about the secondary character.

Indeed, Derek hoped that those Society members who heard his public talks or read his articles in the journal would subsequently 'know who Richard is, and what he is and where he came from.' That drive to know is fuelled by what readers find on the pages of the novels but also by what is missing from them. In our conversations and in his after-dinner talk on Richard Maddison, he kept highlighting a period of ten years, from the age of sixteen to twenty six, when the novels seem to provide no information. 'All that time, those formative years, and nobody knows what he did,' Derek mused to his audience.

This wistfulness comes from the fact that much of the labour that Derek and others describe is precisely about recovering the biography of minor character. Certainly, piecing together a life and personality structure the tone and narrative shape of many public talks. At another Redhill meeting, Grace, a Society member from a village in West Sussex, provided us with "Theodora" - an initial look at Phillip's aunt in the Chronicle.' Her talk began with a confession that she 'has been thinking about Theodora for several years now,' and that she 'likes and admires her.' The character, she told us, endures across the novelcycle, featuring to varying limited extents in every volume. 'But what was she like?' Grace asked rhetorically. The rest of her lecture sought to outline an answer through a chronological exploration of what we can know. Theodora, Grace stated, was attractive to look at, with blue eyes and fair hair, slender fingers and a soft voice. She was an independent woman for her time, someone who refused to wear a corset, a 'caring person' with a social conscience that later led her to become a suffragette and work with the poor in the East End of London. Each stage of her life was illustrated with quoted extracts from the Chronicle, which Grace read with considerable feeling; in the last passages even reproducing the frail voice of the old woman Theodora had by then become. 
Much like Derek, she ended her public talk by highlighting the blanks; 'but what of the other aspects of Dora's story, we may never know,'

Of course biographical exposition does not preclude acknowledgement of what Woloch terms the structural relationship to narrative discourse. Society members pepper their public talks with asides about the role and function of minor character in the novels. The woman who rose to talk about her favourite character Spectre West at the branch meeting I attended, for instance, started by highlighting that West was a 'device'. The character was there, she told us, to 'provide the reader with a history of The Great War.' He was also there, she continued, to give us fresh perspective on the protagonist; 'Westy's role is to help with Phillip's own development... he helps us see how Phillip changes.' This idea of minor characters being in service to the character evolution of major characters is a common theme. Frequently, these character roles are conflated with kinship roles. In her study of other secondary characters in the Chronicle, Grace gives an account of the lives of the protagonist's mother and wife. Both women, we are told, 'see their role as caring for Phillip' and it is through this maternal or wifely attention that they exercise influence on his characterdevelopment. Likewise, Derek reflected during his public talk on the way Richard Maddison throws perspective in multiple directions through kinship. 'Richard's chief role in the Chronicle,' he declared, 'is to be the villain, the stern husband and father, unlikeable, unreasonable, unbending, unforgiving, uncompromising, unkind... the man who nearly wrecked the lives of his wife and children.'

But just as it is suspected that the individual person of Richard Maddison must also exceed the persona of husband or father, so, Society members hold, the functional role of minor character in the narrative discourse of the novels is never a sufficient explanation of their existence or fascination for readers. As the work of biographical exposition highlights, it is the implied person that lies behind the character that for them really counts.

In fact I want to argue that the private study and investigation of minor character is first and foremost a form of rescue. Society members are driven by an acute sense of these characters' neglect, which includes an awareness, to quote Woloch (2003: 25), that 'the actualization of a human being is denied.' That denial can occur, to cite Woloch again, through the ways in which the consciousness of minor characters can be felt as 'drowned out' by the consciousness of major ones. In her attempt to recover the life of Lucy Maddison, the wife of the protagonist, Grace talked of the importance of locating those places on the page where 'Lucy has a voice of her own and we see Lucy's side of things', as opposed to just seeing her through the dominant perspective of Phillip. But here actualization is also about recognising the neglect of other Williamson readers, their tendency to dismiss some female characters as for instance weak; one of Grace's declared ambitions was to make members see that 'these gentle creatures were no cardboard cut-outs but very much their own selves.' A similar motivation prompted the investigations of Derek. He told me that he felt Richard Maddison was a 'neglected fellow', someone other Society members were afraid to take on. In part, this was because he appeared across the fifteen volumes of the novel-cycle and so readers 'can only take him piece by piece'; however, the bigger reason was that readers were put off by his persona or role in the novels. 'If I can spotlight Richard,' Derek told me, 'help other 
people to focus on his life and times, and to understand the guy and sympathize with him, laugh at him and laugh with him, then I shall be happy.'

The work of actualization is also grounded in a conviction about the reality of minor character. Derek insisted that 'Richard was a very sorry fellow in many ways, but he was convincing, he was a real character, a real person.' Indeed, that conviction is sometimes presented as the very basis for a shift from attending to the role or structural position of character to attending to its hinted at reference to human being. In response to questions from the audience after her public talk on Theodora, Grace revealed that at first she wondered whether the character was just a literary device, 'the social conscience of the novels'. That sense of something more and the sympathy for minor character that develops with it is said to grow through rereadings. 'When I first started I had no sympathy for Richard,' Derek told me, 'I thought, "Oh he's such a miserable old devil, and he's only the hero's dad anyway, no one need take much notice of him"'. The need for rescue then is not an immediate impulse.

While retrospective biographical recovery dominates the private studies and public lectures of Society members, it is not the only basis for actualizing secondary characters. The speaker at Redhill who chose Mrs Low and her family as his favourite also spoke of the importance of imagining futures for those 'very minor' characters in the Chronicle who only make the briefest of appearances on the page. 'I imagine that the husband dies well before his wife,' he told us, 'that the son Lenny is killed in the war and the mother Mrs Low dies in old age a sad old relic.' Actualization and a sense of the hinted at person's reality is also achieved through moments of self-identification. Derek told me that one of the reasons his sympathy grew for Richard Maddison over time was because he began to see parallels between their two lives. 'Richard, like me, came from a small village and then moved to a strange and confusing big town,' he explained, 'and like Richard, I was sent off to boarding school.' Here the reality of his own lived experience seems to help actualize or confirm the reality of the experience of Richard. Grace made a similar point. 'Perhaps if you have struggled yourself with several small children,' she told the Society audience, 'you have more idea of what Lucy's life must have been like.' The observation then led in the following statement: 'For some readers Lucy may hardly exist, but she is there almost between the lines, and has to be hunted out.' Part of the power of selfidentification as a technology of actualization lies in the fact these parallels are often unsolicited by the reader, that they take them by surprise and hence seem to have a quality of objectivity.

Finally, actualization also seems to be an effect of the act of character judgement itself; a core element of biographic exposition in public talks. The point is nicely illustrated once again by Derek, who literalizes the idea of judgement both in his account of the distributed field of attention and neglect within narrative discourse and in his desire to highlight the impactfulness of human being. At the end of his forty minute address to Society members, he concluded by inviting the audience to 'review the evidence' against Richard Maddison.

So I have put him in court on trial for his many shortcomings. The charges are read out by the clerk 'How do you plead?' Richard bows to the judge: 'I am what I am, m'lud'. The judge: 'And who are all these people?' The clerk: 'Witnesses, m'lud- the accused's grandfather, his parents, his in- 
laws, his brothers and sisters, his wife and children, his neighbours, the vicar, his childhood nanny, his old landlady...' The Prosecution: 'We have examined the evidence, m'lud, and declare that the accused has been in turn... a fool_and a scamp and a niminy-piminy dressed up son of a drunken wastrel, a poor fish, with no sense of humour... We are confident that the jury will find against this man, and we will ask for the highest penalty that the law can provide'... The Defence: 'We have also sifted the evidence, m'lud, and have found that Duty and Decorum have been the ruling abstracts of this man's life, he is a product of Victorian respectability, a stern believer in moral values and discipline... Lastly, m'lud, we would respectfully suggest to the jury that there is much of the accused in all of us, and in conclusion would say that we are confident that this innocent man will be discharged without a stain on his character. The tone may be tongue-in-cheek, but Derek intended the invented scene to highlight the potential role of minor characters in the novel-cycles as 'characterwitnesses' (he has Richard's grandfather, parents, in-laws, brothers and sisters, wife and children, neighbours etc. all provide evidence for and against the accused). He also intends his audience to take on that role, to figure them and Williamson readers in general as subjects who must decide. 'Well, ladies and gentlemen of the jury,' he looked around at us before uttering his final words, 'how do you find?'

\section{Character-source:}

But the most crucial motivator for minor character investigation comes from the revelation that many of these secondary characters are in fact based on historical persons. Indeed, individuals identify this knowledge as one of the most significant outcomes of membership. While it was always clear that some minor characters in the novel-cycle were drawn on famous figures from the past, such as leading generals in the First World War, readers had little idea that many of the other characters were based on persons either known or related to the author. This information was first communicated to them by other Society members and reinforced by the authority of the author's literary estate, whose representatives have played a central role in the Society since its inception.

Not surprisingly, the public acknowledgment of a historical source for minor character has been an essential aspect of the drive to actualize, both confirming readers' sense of the implied or 'real' person that lies behind character and inspiring further acts of studious re reading. It is also a core part of the biographic exposition that members provide in their lectures and journal articles. When Derek spoke, for example, he began by asserting that 'We know the character of the fictitious Richard Maddison (1866-1946) is drawn directly from that of the author's own father William Leopold Williamson (1865-1946).' By way of illustration, he then picked up and displayed to his after-dinner audience an A4 sized blow-up photograph of Henry Williamson's father at age fifty, dressed in a tunic and army cap. Grace did the same thing in her talk on Theodora, projecting a photograph of Mary Leopoldina Williamson on the screen, which she told us she had taken from the official biography. As well as instantiating the source for minor character in this way, public talks often proceed through an act of comparison between the life course of the character and the life course of the now historically identified implied person. 'Both were 
bank clerks in the City,' Derek told us, 'both their mothers were German ladies named Adela, both were married when aged twenty-seven at Greenwich Registry Office.' But in this comparative work, difference is as important as similarity. Grace, for instance, highlighted that Williamson's paternal aunt actually lived in the North Devon village of Georgeham, not, as it appears in the novels, in Lynmouth. Photographic illustration can also serve to emphasis difference; Grace told her audience at Redhill that when she first saw the image of Mary Leopoldina, formally dressed in late Victorian costume and looking reserved, she was shocked because it was not how she had imagined Dora. The invocation of 'fictional additions', to borrow a phrase from Derek, had the value of showing where characterization began.

If the private research of Williamson readers is partly about retrospectively rescuing character-source, what one member described to me as the task of putting 'flesh and bone on the characters,' then it is important to point out that such practice marks a dramatic shift in readerly engagement. Before joining the Society solitary readers tended to view minor characters in the context of the novels and the experience of reading them, but now they also viewed them through the historical figure that suddenly appeared to exist prior to the act of characterisation. The implied person seemed to have a literal life outside the novel. Uncovering that historical person, a prompt to future investigation and re reading, gave a new and very specific sense of the impactfulness of human being. In a very tangible way, it also re-emphasized a sense of what literature denies: i.e. that which is found in the character-source but not reproduced in character. Rescuing that information may show-up the gap between them; however, for Society members it also seems to grant minor character an autonomy, and, once folded back into the 'fictional additions', to allow for secondary character expansion.

The kind of comparisons practised by Derek, Grace and other Society members, and the kind of private research that flows from identifying a historical character source, bear an obvious resemblance to the hugely popular work of hobby genealogy. Like those motivated to trace their own particular family line, this form of research leads Williamson readers to visit libraries and archives, to investigate online genealogy resources and to read local social history in order to find out more about the specific historical figure that they believe or have been told lies behind a minor character. Sometimes they literally apply genealogical technique to the presentation of secondary characters; at Derek's public talk on Richard Maddison, for instance, he revealed the family tree he had constructed for the Maddison family, projecting it on a screen alongside a generational diagram of Henry Williamon's family members provided by the literary estate. If the thrust of amateur English ancestor genealogy is to discover where one has come from (see Cannell 2011: 462), then it is possible to immediately grasp the analogy to the work of actualization. Indeed, as Cannell (2011: 465) points out, the effect of genealogical research is often to 'enliven' the dead as persons and to 'reconnect' them to the living as kin. This labour, Cannell argues, 'permits a deceased relative to be apprehended as a real person by their descendant- to become, as it were, actual rather than potential family' (2011: 469). In the case of Society members' research, the effect of enlivening the dead as persons is not so much to reactivate a relationship to the living (i.e. to either the researcher or to the family of the deceased) but rather to the dead as 
character (to whom the living, in the form of the Williamson reader, have a relationship). In fact, I want to argue that this work provides Society members with a sense of the dead or historical person as someone who enables a new kind of attention to be given to minor character.

Cannell also talks of English hobby genealogy as a form of 'care for the dead' (2011: 472). But crucial to that relationship, she insists, is a sense of reciprocity; to many amateur researchers she met it felt like 'the dead in return are transmitting a token of care, a gift of kinship continued into the future' (2011: 473). The observation is important, I think, because it draws us to the fact that once a relationship between minor character and historical person is identified, the flow of care or attention can potentially be acknowledged to move both ways. In other words, minor character can appear to give new attention to the source, to almost be a way of actualizing the previously only hinted at person of the deceased.

Turning back to the work of Gell (1998) can perhaps help make the point. In his re-theorization of the anthropological approach to art, he grounds his analysis not just in the primacy of the patient position, but in the wider dynamic of relationships that are taken to demonstrate agency. It is not only actions suffered upon or through a figure that matter; the ways in which those flows of agency can be redirected are equally important. In a common strategy, Gell provides an example from outside the Euro-American context of art production in order to then reapply the methodological insight to more familiar artworks.

Volt sorcery (for example, sticking pins into a wax statue), Gell tells us, is a practice 'in which an image of the victim is made, subjected to injury or destruction, with the result that the victim of the sorcery suffers the same injuries or is done away with entirely' (1998: 102). Viewed through his analysis of effectual actors, what immediately stands out is that this is a form of sorcery predicated on the reversibility of cause and effect between an image and the person represented. (1998: 103). As Gell highlights, 'the victim appears twice'; the first time as the 'prototype' or person depicted whose appearance causes or makes him or her responsible for the particular shape the image takes, and then a second time as the receiver of the image, whose own injuries result from the damage that object suffers. So while the sorcerer may demonstrate intentionality, the victim of that sorcery also exercises a kind of 'involuntary agency' (1998: 106) in the exchanges that take place through the image. Once again, this is exemplified in the moment causal effect is seen to flow in the opposite direction and the victim of volt sorcery shifts, from being identified as the unwilling 'contributor of something' to being recognised as the 'recipient of something'.

For Gell, such an example rests not so much on a 'magical principle of causation' but rather in a 'more literal-minded exploitation of the predicament of representability in image form' (1998: 103). As he points out, it is not conventional in art theory, where semiotic notions of representation dominate, to consider images such as portraits as 'parts of the persons' depicted (1998: 104). But this is precisely what Gell invites us to do, and what he claims animates engagements with artworks. In his desire to undermine the primacy assigned to representation (or better put, to render representation as specific and dynamic causal relationships between image and the source of depiction) and to listen closely for the voluntary and involuntary agents identified, he finds a new 
equivalence between examples. In this approach, 'it is not senseless to suppose that Constable's picture of Salisbury Cathedral is a part of Salisbury Cathedral'. Likewise, the forms of involuntary agency that may animate a portrait or the image in volt sorcery can both be taken to illustrate a 'distributed personhood', where the person depicted exists and is composed in the body but also in the dispersed milieu of 'detached fragments' (such as a painting or a statue) beyond it.

The idea that the subject represented or depicted in an artwork may exhibit diverse forms of involuntary agency is particularly useful for our purposes. As is the broader point that these claims around the identification of source are eventful and, like other shifts or redirections in the flow of causality, must be read in time. Society members report that once the historical person depicted in minor character is recognised then the continued work of uncovering that figure seems to say more and more about that character; a fact that contributes to the effect of the dead person's agency. As the length of time devoted to character-source in public talks illustrates, this can lead to a situation where Williamson readers feel they know more about the person depicted than the character on the page. The particular work of actualization embodied in this historical or genealogical research therefore also risks diminishing minor character; a move originally conceived as a way of bolstering the impression of a real person behind character is in danger of drawing attention away from it. So much so that Williamson readers sometimes appear to need to do rescue-work in reverse. It is not uncommon to hear Society members insist that although they do this research, it is not necessary to an appreciation of the novels. For some, it is almost as though they want to make literary character reappear as the base or source of historical persons, which is of course the proper order in which they actually encountered these two causally-linked figures.

The tension also informs an important ontological difference in the relationship Society members can have to minor character and the dead person it depicts. For when Williamson readers join the Society, they not only discover the facts of character-source, but also they meet a minority of readers who were aware of those facts from the beginning (i.e. before they started reading the novels). These members explain that they came to the volumes of the Chronicle precisely because they knew they contained a fictionalized account of historical persons and events; for instance, of persons where they grew up, in their local area (usually either South London or North Devon), or of teachers at the school which they, like Williamson, once attended. Indeed, they give public talks and publish journal articles on these directly experienced or inherited reminiscences. For such readers, the journey is markedly different. They first confront character as versions of historical persons they knew or knew of, who existed for them prior to their fictional representation. So part of the pleasure of reading and re reading Williamson came from seeing those persons depicted as minor characters, as in some way flattened or expanded indexes of people they remembered. The tension derives from the relationship of historical persons to an implied character, this time actualized by Williamson.

\section{Conclusion:}

Of course what remains unsaid in both these forms of minor character investigation is the fact that the central consciousness of the Chronicle series is 
also based on a historical person. But this is not just any old character-source; as the traced relationships Society members make between the fictional family of Phillip Maddison and the family of Henry Williamson might suggest, it is widely accepted that the person depicted in the lead character is the author himself. The realisation that Phillip Maddison is based on Henry Williamson is presented as one of the accomplishment of Society membership; indeed, it informs the particular ways in which this literary society carries out the core labour of promoting the writer and his works. Exploring the biography of Williamson, for instance, a typical kind of activity for any literary society, is always infused with the knowledge that this will feed into or influence understandings of the protagonist's hinted at human being. However, Society members must also acknowledge an asymmetry between this relationship and the relationships that secondary characters bear to their historical counterparts. For the historical person depicted as Phillip Maddison is not a straightforwardly involuntary agent in the shaping of the protagonist's character; he is at one and the same time the figure that intentionally creates or authors the novels and all of the characters contained therein. This is an obvious complication to the presentation of implied person as either the contributor of something to character or the recipient of something from character. To Society members, Henry Williamson appears more than twice, from within the dynamic relationship between protagonist and prototype and from without, as the person who orchestrated the distribution of attention across narrative discourse.

But in all these convoluted negotiations of patient-agent relations, the investigatory culture of Williamson readers rarely operates through overt expressions of readerly agency. The Society members I knew would completely reject the suggestion that they have primacy in the constitution of any culture of reading that we may allocate to them. As we have seen, the role of the reader is rather like the structuring role assigned by Woloch to minor character in the field of narrative discourse: i.e. to throw attention elsewhere. Williamson readers publicly perform this role in their collective work as members of a literary society dedicated to promoting or giving attention to the works and life of Henry Williamson. And they perform it individually in their private labours of investigation, which, to quote Derek again, is driven by a concern to 'spotlight' favourite character. For them, the latter is achieved by throwing attention on the historical person behind character, and by highlighting the attention-giving and attention-receiving tension between character and its source.

Indeed, it remains unusual to hear Williamson readers spotlighting themselves or each other. Even those moments when they self-identify with secondary characters seem to revolve around a claim that either reinforces the convincing nature of that literary character or draws attention to the skill of the writer in capturing the universal essence of a feeling or incident. Likewise, Society members often told me that they know very little about the individual lives of other Williamson readers in the literary society. The point is typically emphasized when a member dies; the persons sent to represent the Society at his or her funeral will usually write a report in the newsletter expressing surprise at all the aspects of the deceased's life that until that event they knew nothing about.

But the apparent impersonality of relationships between readers in the literary society belies a great and much appreciated sense of camaraderie or 
fellowship. This is acknowledged to be the outcome of, in many cases, years of sociable exchange at Society events and of the shared enthusiasm for the works of Williamson that first brought them together. However, the intensity of that fellowship cannot be explained by what readers do collectively; Society members consistently emphasize that it principally derives from the mutuality of experience in the initial enraptured act of solitary reading. Minor character investigation and the other forms of Society activity come after this event; they must ultimately be understood in its orienting wake. It is also in the drama of this moment that readers do identify a kind of spotlight on themselves, as the recipients of a certain kind of attention from Henry Williamson.

It may seem strange to conclude this essay by looking at what, for nearly all Society members, began this culture of reading. However, for me, deferring that account has allowed a space for the description of secondary reading practices such as minor character investigation that might otherwise disappear. While these practices are literally prefigured by the act of enraptured reading, that event cannot explain or fully contextualize where those practices take readers. It is true to say though that Society members continue to draw strength from the initial solitary experience of authorial possession (see Reed 2011). It is this alien or borrowed attention (i.e. what they figure as the internally consumed consciousness or perspective of Williamson) that Society members assume to be the basis of their fellowship. The fact that there is no need to inquire into the individual life of other Society members in order to get to know each other, because connection through shared intimacy with or knowledge of 'Henry' pre exists their formal meeting, gives readers the time and space to concentrate their energies elsewhere. Indeed, there is a sense in which the minor status that readers embrace is itself an artefact of enraptured reading. By internalizing the dominant consciousness of the author, readers seem to lose the need to identify or make contact with an implied person behind each of their fellow members. It is almost as though 'Henry' substitutes for that hinted-at human being. Finally, the reassurance generated by the warmth of this camaraderie seems in turn to reassure them about the character of Williamson. He can't have been such a bad person, members muse, if he brought so many of them together.

\section{Acknowledgements:}

My thanks, as always, to the members of The Henry Williamson Society. I am very grateful to Evelyne Ender and Deidre Lynch for the invitation to contribute to this issue, and for the consistently helpful feedback throughout the process. A version of this essay was given at the Social Anthropology Department Seminar, University of Cambridge, and I am also grateful for the comments I received there.

\section{References:}

Cannell, Fenella. 2011. 'English Ancestors: the moral possibilities of popular genealogy,' Journal of the Royal Anthropological Institute 17(3): 462-480.

van Eck, Caroline. 2015. Art, Agency and Living Presence: from the Animated Image to the Excessive Object. Leiden: Leiden University Press. 
Fortes, Meyer.1962. 'Ritual and office.' In Essays on the Ritual of Social Relations, edited by M. Gluckman. Manchester: Manchester University Press

Henare, Amiria, Holbraad, Martin \& Wastell, Sari [eds.]. 2007. 'Introduction,' in Thinking Through Things: Theorising Artefacts Ethnographically. New York:

Rouledge

Gell, Alfred.

1992. 'The Technology of Enchantment and the Enchantment of Technology.' In Anthropology, Art and Aesthetics. J. Coote \& A. Shelton [eds.], 40-66. Oxford: Clarendon.

1998. Art and Agency: an anthropological theory. Oxford: Clarendon Press.

Johnson, Claudia. 2012. Jane Austen's Cults and Cultures. Chicago: University of Chicago Press.

Reed, Adam.

2002. 'Henry and I: an ethnographic account of men's fiction reading'. Ethnos 67 (2): 181-200.

2004. 'Expanding "Henry": Fiction reading and its artifacts in a British literary society'. American Ethnologist 31: 111-122.

2011. Literature and Agency in English Fiction Reading: a study of Henry

Williamson Society. Manchester: Manchester University Press \& University of Toronto Press.

Strathern, Marilyn. 1999. Property, Substance and Effect. Cambridge: Cambridge University Press.

Woloch, Alex. 2003. The One Vs The Many: Minor Characters and the Space of the Protagonist in the Novel. Princeton: Princeton University Press. 
${ }^{1}$ Gell does not explore the position of the recipient in literature or indeed include literary works in his discussion of art; that is entirely my innovation. Indeed, I make no claim to be providing or advocating for an authoritative interpretation of Gell, only to finding some inspiration in the way he handles the question of who acts in the vicinity of art.

${ }^{2}$ Another legacy of Gell's approach is a focus upon art as a particular kind of 'technology'. In a much-cited earlier essay, this claim was closely tied to an analysis of the technical virtuosity of the artwork as it is taken to enchant the viewer (Gell 1992; \& see van Eck 2015: 20). But in Art and Agency, the term operates more implicitly and with much broader effect, to reinforce Gell's general provocation to think of art as a system of doing instead of just as a system of aesthetic value or signification. It is in this latter sense that I invoke the term here, to capture both the specific technique of minor character investigations and the system of action that I take to underpin them. 